\title{
A LINGUAGEM ESTÉTICA COMO DANO POLÍTICO EM JACQUES RANCIÈRE
}

\author{
AESTHETICS LANGUAGE AS A POLITICAL WRONG IN JACQUES RANCIÈRE
}

${ }^{1}$ Flávia Souza Máximo Pereira

${ }^{2}$ João André Alves Lança

\section{RESUMO}

O presente artigo analisa aspectos da linguagem estética enquanto dano político, mediante a concepção de política e estética presentes na obra do filósofo francês Jacques Rancière. Primeiramente, utilizando o tipo de investigação jurídico-interpretativo, o conceito de política de Jacques Rancière é analisado, compreendido como forma de ruptura da distribuição hierárquica de corpos e funções na configuração do sensível. Posteriormente, é examinada a relação entre o referido conceito de política, o dano que lhe é próprio e a linguagem estética, como sendo o instrumento que se manifesta em crítica e resistência capaz de romper com a ordem pré-estabelecida. Por fim, são mencionados alguns exemplos da linguagem estética enquanto dano político.

Palavras-chave: Linguagem, Estética, Política

\begin{abstract}
This article analyzes aspects about the aesthetic language as a political wrong through the concepts of politics and aesthetics of the French philosopher Jacques Rancière. First, using the legal-interpretive method, the concept of politics developed by Jacques Rancière is analyzed, comprehended as a way to break the hierarchical configuration of bodies and functions in the sensible distribution. Afterwards, it is examined the relation between this definition of politics, its wrong and the aesthetic language, as a instrument that manifests itself in criticism and resistance able to break with the pre-established order. Finally, are mentioned some examples of aesthetic language as political wrong.
\end{abstract}

Keywords: Language, Aesthetics, Politics

\footnotetext{
${ }^{1}$ Doutoranda em Autonomia Individuale e Autonomia Collettiva pela Università degli Studi di Roma Tor Vergata UNIROMA, Roma (Itália). Estagiária de Docência pela Universidade Federal de Minas Gerais - UFMG, Minas Gerais (Brasil).E-mail: flavia_maximop@yahoo.com.br

${ }^{2}$ Mestre em Direito pela Universidade Federal de Minas Gerais - UFMG, Minas Gerais (Brasil). Consultor pela Malab Araújo Consultores e Advogados - MALAB \& ARAUJO, Minas Gerais (Brasil).

E-mail: joaoandre7@hotmail.com
} 


\section{INTRODUÇÃO}

O presente artigo filia-se à vertente jurídico-teórica e busca analisar os aspectos conceituais e doutrinários da linguagem estética enquanto dano político, mediante as concepções de política e estética presentes na obra do filósofo francês Jacques Rancière.

Analisa-se, primeiramente, o conceito de política elaborado por Jacques Rancière, concebido como atividade que desfaz a distribuição de corpos e hierarquias que definem os modos do fazer, os modos do ser e os modos do dizer na configuração pré-ordenada da realidade, ou na configuração da divisão do sensível, na expressão do autor. A política, conforme Rancière, é a atividade que desloca um corpo do lugar que lhe era designado ou que muda a destinação de um lugar; ela atribui visibilidade ao que é invisível; faz ouvir como discurso o que era só ouvido como barulho.

Rancière destaca como instrumento de manifestação da política e ruptura da divisão do sensível a linguagem estética, em seu aspecto poético e metafórico, como mecanismo desarticulador das formas intramundanas de argumentação e validação.

As linguagens metafóricas oferecem-se como tal instrumento na medida em que manifestam potencialidades próprias da política, as quais são sempre, ao mesmo tempo, argumentação e abertura para se questionar as condições em que essa argumentação é recebida no mundo.

O efeito da expressão estética das modalidades de relações de poder tem o potencial de gerar encontros de teor político (reconfiguração do sensível), quando torna o que era banal e anônimo em objeto de arte, atribuindo-lhe visibilidade efetiva. O dano político pode, nesse sentido, ser impulsionado por manifestações estéticas de diversos tipos, não apenas pelas manifestações de estirpe literária, mas também por meio da música, do teatro, da dança, do grafite, de performances e entre outras formas. Assim, a estética tem o potencial de ação transformadora, de verificação da igualdade e de distribuição do comum, uma vez que é capaz de fazer sentir e ver a posição dos corpos na "pólis" e, com isso, desvelar ordens opressivas e excludentes.

Desse modo, busca-se mediante a linguagem estética, ressaltada como uma forma de dano político, nos termos de Jacques Rancière, contribuir para se pensar ações políticas alternativas. São abordados, para tanto, exemplos de performances estéticas desencadeadoras 
desse tipo de reflexão, como no caso do flash-mob que foi utilizado por trabalhadores alemães para reivindicar melhores salários ou no caso da denúncia de práticas discriminatórias veladas, como foi evidenciado no movimento "Senzala Nunca Mais" e na Parada do Orgulho LGBT da cidade de São Paulo.

Desse modo, demonstra-se que a atividade política por meio da linguagem estética é um modo de manifestação que pode confrontar o fluxo padrão da ordem policial que cria e mantêm subalternidades.

O objetivo, por fim, não é apontar a linguagem metafórica como evidência de um esfacelamento fatalista da heterogeneidade dos jogos de linguagem e dos pontos de partida que limitam os discursos, como se não se pudessem mais produzir pretensões narrativas (ou metanarrativas) em âmbito político. Ao contrário, o que se busca é colocar a questão de que essa heterogeneidade e, assim, o desentendimento, revelados com mais força pela manifestação estética, ao invés de obstáculos externos a serem curvados, são fatores constitutivos da vida política, que convocam para se assumir o dano da existência de uma comunidade efetivamente dividida, no sentido de compartilhada.

\section{O CONCEITO DE POLÍTICA DE JACQUES RANCIÉRE}

A caracterização política do homem se liga a um indício: a posse do logos, isto é, da palavra que manifesta, e não somente da voz (phoné) que apenas indica. Esse é o ponto de partida de Rancière (1996), no primeiro capítulo de sua obra "O Desentendimento: Política e Filosofia", no qual inicial lembrando as frases de Aristóteles, no Livro I da "Política":

[...] o homem é o único entre os animais que tem o dom da fala [possui a palavra].
Na verdade, a simples voz pode indicar a dor e o prazer, e outros animais a possuem
(...), mas a fala tem a finalidade de indicar [manifestar] o conveniente [útil] e o
nocivo, e portanto também o justo e o injusto; a característica específica do homem
em comparação com os outros animais é que somente ele tem o sentimento do bem e
mal, do justo e do injusto e de outras qualidades morais, e é da comunidade de seres
com tal sentimento que constitui a família e a pólis (ARISTÓTELES, 1985, p. 1253
apud RANCIĖRE, 1996, p. 17).

A posse da palavra marca a separação entre duas maneiras de se participar no mundo: a do prazer e da dor, comum a todos os animas dotados de voz; e a do bem e do mal ou justo e injusto, que advêm da percepção do útil e do nocivo, inerente apenas aos homens (RANCIÈRE, 1996). A organização dos homens na pólis se desenvolve a partir dessa 
capacidade de manifestar o útil e o nocivo e o justo e o injusto. É por ela que se definem os lugares dos seres humanos no espaço da pólis.

Essa disposição de corpos no estar-junto humano sempre obedece, em razão disso, para Rancière (1996), a uma lógica pré-ordenada de modos de ser, modos de fazer e modos de dizer que são convenientes para a manutenção de uma divisão da realidade. Essa configuração, denominada por Rancière de divisão do sensível, determina a distribuição dos corpos no espaço. Tal distribuição, por sua vez, coloca os corpos em lugares de visibilidade ou de invisibilidade, nome ou sua ausência de nome (reconhecimento), tendo em vista uma atribuição de caráter lógico ou fônico aos sons que tais corpos produzem (RANCIÈRE, 1996, p. 40).

Esse quadro de divisão do sensível, todavia, não é exatamente a política para Rancière (1996). A política não é o estado das coisas. Rancière (1996) olha para os "clássicos" (Platão e Aristóteles) e enxerga que a consciência política nasce do movimento de passagem do útil para o justo, o que significou deixar de organizar a vida em sociedade pela lógica do equilíbrio de lucro e perdas, do mero vantajoso e do desvantajoso. Nesse movimento, buscou- se uma justiça consistente em dar a cada um a parcela que lhe cabe e, assim, estabelecer uma divisão do comum, uma divisão da pólis. Em suas palavras,

A política começa justamente onde se pára de equilibrar lucros e perdas, onde se tenta repartir as parcelas do comum, harmonizar segundo a proporção geométrica as parcelas de comunidade e os títulos para se obter essas parcelas, as axiai ${ }^{l}$ que dão direito à comunidade. (RANCIÈRE, 1996, p. 21).

O autor identifica que essa pretensão de justiça política (redistribuir o comum), nos "clássicos", deu-se com o pensamento de se passar da lógica aritmética para a lógica geométrica, que significou a transição da idéia de troca para a "elevação" da idéia do bem comum, que se exprime no imperativo de cada um ter e cumprir a sua parte (parcela) para a promoção desse bem. Explica Rancière:

\footnotetext{
[...] para os fundadores da filosofia política, essa submissão da lógica trocadora ao bem comum exprime-se de maneira bem determinada: ela é submissão da igualdade aritmética que preside as trocas mercantis e as penas judiciárias, à igualdade geométrica que, para a harmonia comum, coloca em proporção as parcelas da coisa comum possuídas por cada parte da comunidade à parcela que ela traz ao bem comum. (RANCIÈRE, 1996, p. 21).
}

\footnotetext{
1 Títulos, valores de comunidade. Aristóteles enumera três: a riqueza dos poucos (os oligoi); a virtude ou a excelência (areté) que dá seu nome aos melhores (aos aristoi); e a liberdade (a eleutéria) que pertence ao povo (demos). Concebido unilateralmente, cada um desses títulos fornece um regime particular, ameaçado pela sedição dos outros: a oligarquia dos ricos, a aristocracia das pessoas de bem ou a democracia do povo. Em contrapartida, a combinação exata de seus títulos de comunidade proporciona o bem comum (Rancière, 1996, p. 21).
} 
A política, assim, para Rancière (1996), é esse móvel de pensar a parcela e o lugar de cada um na pólis, para adiante da dimensão imediata da troca de lucros e perdas ou de fortes e fracos. Foi o que ocorreu, por exemplo, quando se instalou a democracia grega e o aparecimento das figuras do povo e dos cidadãos, que passaram a ser assim considerados, independentemente da posição material cada um.

Isso é feito, segundo o autor, porque entra em cena um segundo efeito do logos - o da contagem. O logos (palavra) nunca é apenas palavra. Ao manifestar o que é justo e o que é injusto, o logos é também contagem que é feita da palavra. Isso significa que o logos sempre faz uma contagem de qual voz é também palavra, e assim compatível com o justo, e quais emissões sonoras designam apenas prazer ou dor, consentimento ou revolta. Na explicação de Rancière:

(...) Logos nunca é apenas a palavra, porque ele é sempre indissoluvelmente a contagem que é feita dessa palavra: a contagem pela qual uma emissão sonora é ouvida como palavra, apta a enunciar o justo, enquanto uma outra é apenas percebida como barulho que designa prazer ou dor, consentimento ou revolta (RANCIÉRE, 1996, p. 36)

Essa contagem, no entanto, argumenta Rancière (1996), é sempre uma falsa contagem. Para o autor, se os "clássicos" ensinaram que "[...] a política não se ocupa dos vínculos entre os indivíduos, nem das relações entre os indivíduos e a comunidade, [mas] ela é da alçada de uma contagem das 'partes' da comunidade [...]", essa “[...] contagem é sempre uma falsa contagem, uma dupla contagem ou um erro na contagem.” (RANCIÈRE, 1996, p. 21-22).

Essa é uma falsa contagem porque o logos sempre "deixa escapar" parcelas que não considera parcelas, isto é, sempre sobram não-parcelas, que são aqueles considerados não falantes ou apenas emissores de som de dor ou prazer, consentimento ou revolta, detentores somente de voz. É o caso dos escravos na democracia grega, os quais não eram contados como parcela que dividia algo comum (a comunidade da pólis), não eram cidadãos, porque não lhes era possível a palavra, que garante a participação no juízo do justo e do injusto.

Assim, para Rancière (1996), a distribuição simbólica de corpos na configuração do sensível está, constantemente, sobre essa tensão entre as parcelas daqueles que realmente falam, dotados de logos, e daqueles aos que se reconhece apenas uma voz articulada.

É nessa tensão entre parcelas e não parcelas o lugar no qual se instaura a política, segundo Rancière (1996), uma vez que esta é o movimento de contagem de parcelas na comunidade. A política é capaz de medir e alterar o afastamento da palavra e da contagem, enfrentando a contradição de dois mundos acoplados em um só: o mundo onde há os seres 
falantes e contáveis e aqueles que não são reconhecidos como tais. Assim, a divisão do sensível, que ordena a configuração das ocupações e das propriedades dos espaços em que essas ocupações são distribuídas, pode ser desfeita e reconfigurada mediante a atividade política, pois o móvel desta está sempre em fazer a contagem de parcelas, antes não consideradas como tal ou pelo menos não com o mesmo reconhecimento. A política é a atividade que visa dar a cada um o seu lugar na pólis, não, porém, manter o lugar pré- estabelecido, por isso, é potencial reconfigurador da divisão do sensível, na visão de Rancière (1996).

Nisso consiste a política para Rancière (1996), desde os "clássicos". A política é a atividade de redistribuição do sensível pela inclusão de parcelas ou pela contagem de novas partes. Ela é o movimento de consideração das parcelas no lugar de compartilhamento da vida na pólis. Quando se buscou a justiça geométrica, dando a cada um o seu lugar conforme o bem comum da pólis, em substituição do determinismo da aritmética das trocas, o que se pretendeu foi reordenar os lugares na comunidade e suas parcelas. É por essa perspectiva que olha Rancière (1996), segundo a qual a política está nesse gatilho de reordenação e não na posterior manutenção da ordem de distribuição geométrica dos corpos no espaço comum.

Rancière (1996), por isso, para enfatizar esse princípio constitutivo da política, propõe nomearmos polícia o que geralmente consideramos ser política: o conjunto de processos pelos quais se operam a agregação e o consentimento das coletividades, a organização dos poderes, a distribuição dos lugares e das funções e os sistemas de legitimação dessa distribuição. A palavra polícia, para o autor, designa a ordem dos corpos que define as divisões entre os modos de fazer, os modos de ser e os modos do dizer: são práticas de organização de poderes, lugares e funções e de legitimação de tal sistema, que dependem tanto da espontaneidade das relações sociais quanto da rigidez das funções do Estado. A polícia é uma ordem do visível e do dizível que faz com que essa atividade seja visível e outra não o seja, que essa palavra seja entendida como dicurso e a outra como ruído (RANCIÈRE, 1996, p. 42).

A política, ao contrário, é a atividade (pensamento, consciência, ação) que, para o autor, rompe com a configuração do sensível na qual se define as parcelas e os "sem parcela"; é uma série de atos que reconfiguram o espaço onde as partes, as parcelas e as ausências de parcelas se definem. A atividade política é a que desloca um corpo do lugar que lhe era designado ou muda a destinação de um lugar; ela faz ver o que não cabia ser visto, faz ouvir como discurso o que era só ouvido como barulho (RANCIÈRE, 1996, p. 42). 
Segundo Rancière (1996), nesse sentido, há política quando existem lugar e formas para o encontro entre dois processos heterogêneos: o processo policial e o processo de igualdade. $\mathrm{O}$ processo de igualdade é entendido como o conjunto aberto de práticas guiadas pela suposição da igualdade de qualquer ser falante com qualquer outro ser falante e pela preocupação de averiguar esta igualdade (RANCIÈRE, 1996, p. 43). É a afirmação da igualdade de todos enquanto falantes e, assim, capazes de participar do justo e do injusto, que, colocada em confronto com a ordem policial, leva à contagem de parcelas antes não consideradas, isto é, antes apenas dominadas, porque submetidas à ordem do sensível sem qualquer palavra.

Para entender o conceito de política em Rancière (1996), é importante ter em mente ser a política esse movimento de deslocamento do sensível, pela contagem de parcelas excluídas, que acontece pelo encontro litigioso dessas duas lógicas que, para ele, são pressupostas - a da ordenação ou da polícia e a da igualdade entre os falantes. A política não é constituída pela polícia e nem pela igualdade. Para o autor, ela é a atividade que faz o encontro dessas duas lógicas, remodelando a organização dos corpos, pois sem reconfiguração também não há política. Nesse sentido, Rancière afirma que:

\begin{abstract}
A política não tem objetos ou questões que lhe sejam próprios: seu único princípio, a igualdade, não lhe é próprio e não é político em si mesmo (...). O que constitui um caráter político de uma ação não é seu objeto ou o lugar onde é exercida, mas unicamente sua forma, a que inscreve a averiguação da igualdade na instituição de um litígio, de uma comunidade que existe apenas pela divisão (...). Para que uma coisa seja política, é preciso que suscite o encontro entre a lógica policial e a lógica igualitária, a qual nunca está pré-constituída (RANCIÈRE, 1996, p. 44).
\end{abstract}

Justamente por não ter objetos ou questões que lhe sejam a priori pertencentes, Rancière (1996) afirma que nenhuma coisa em si é política. Uma mesma coisa ou conceito, diz o autor, pode dar ensejo à política ou não dar nenhum ensejo; uma opinião ou um direito, por exemplo, pode designar um agir político, caso produza a instituição ${ }^{2}$ de uma reconfiguração do sensível, ou uma manutenção da ordem policial, caso apenas contribua para afirmar a regulação dos modos de ser em prol da ordem já estabelecida (RANCIÈRE, 1996, p.

$45)$.

\footnotetext{
${ }^{2}$ A palavra instituição é importante no conceito de político de Rancière, que a utiliza de um modo específico, para expressar a ideia de que a ação política é aquela que cria uma nova estrutura de fala e participação daqueles que eram sem-parcela. Essa instituição é relevante porque a desordem da revolta também não faz política. Explica Rancière (1996, p. 26-27): "A política existe quando a ordem natural da dominação é interrompida pela instituição de uma parcela dos sem-parcela. Essa instituição é o todo da política enquanto forma específico de vínculo. Ela define o comum da comunidade como comunidade política, quer dizer, dividida, baseada num dano que escapa à aritmética das trocas e das reparações. Fora dessa instituição, não há política. Há apenas ordem da dominação ou desordem da revolta."
} 
O direito é um exemplo clássico, porque vai sempre representar uma dessas duas ações: o de manutenção da ordem policial, podendo ser seu fenômeno mas mais aparente, em razão de sustentar a licitude da coerção física; ou pode ser a expressão de um deslocamento na divisão do sensível, incluindo parcelas ou atualizando a igualdade de fala e o respeito de certos corpos em relação a outros. É o caso do reconhecimento de direitos das minorias, das mulheres, dos homoafetivos, dos indígenas, de hipossuficientes, dentre outros grupos historicamente encarados como subalternos.

A relevância do conceito de Rancière se revela pela radicalidade de seu pensamento frente à filosofia política, rejeitando duas noções de política que já foram esgotadas no pensamento social ocidental: a política entendida como administração governamental do poder e a política entendida como um processo de transformação no qual as estratégias dos oprimidos são decididas por um grupo de experts (GALENDE, 2012 p. 265). A primeira concepção é a expressão do que o autor denomina de polícia, conforme abordado acima. Já a segunda concepção é criticada para que seja superado o processo de vitimização das massas.

\subsection{O Dano Político}

Para Rancière (1996), como visto, nenhum fenômeno social é por si só político, mas pode vir a sê-lo se der ocasião ao referido encontro da lógica policial com a lógica igualitária. E esse encontro remete a um dano. Um dano produzido na distribuição hierárquica dos lugares e das funções que gera relações de opressão e identidades subalternas. A política visa produzir um dano na divisão do sensível a fim de reordená-la. Conforme explica Machado, a política questiona “[...] a naturalidade da distribuição hierárquica das partes. Isto implica em desconstruir, a partir da manifestação de um dissenso, a correspondência policial que naturaliza determinadas categorias sociais e suas funções correspondentes.” (MACHADO, 2012, p. 268).

O dano político coloca em evidência o litígio ou o conflito próprio mesmo da política. $\mathrm{O}$ litígio que institui a cena política, refere-se à existência das partes como partes, a existência de uma relação que as constitui como tal (RANCIÈRE, 1996, p. 39). A política, assim, para Rancière (1996), é primeiramente o conflito em torno da existência de uma cena comum - a da possibilidade de todos os falantes serem contados como parcelas participantes da definição do justo e do injusto. Isso implica atualizar a igualdade frente ao que o autor chama de pura 
contingência da ordem social (todos podem estar no lugar um do outro algum dia). Atualizase a igualdade de qualquer ser falante com qualquer outro ser falante, independente da posição social que ocupem no momento, e isso revela um conflito que o dano almejado pela política deixa claro (RANCIÈRE, 1996, p. 40).

Esse dano, para melhor ser entendido, não é uma troca ou um acerto, mesmo violento, entre parceiros constituídos. O dano é anterior a qualquer trocar, porque as partes não préexistem ao conflito. É o dano que faz surgir as partes na cena comum da sociedade. Isso significa que, segundo esclarece o próprio Rancière:

\begin{abstract}
Não há política porque os homens, pelo privilégio da palavra, põem seus interesses em comum. Existe política porque aqueles que não têm direito de ser contados como seres falantes conseguem ser contados, e instituem uma comunidade pelo fato de colocarem em comum o dano que nada mais é que o próprio enfretamento, a contradição de dois mundos alojados num só: o mundo em que estão e aquele em que não estão, o mundo onde há algo 'entre' eles e aqueles que não os conhecem como seres falantes e contáveis e o mundo onde não há nada. (RANCIÈRE, 1996, p. $40)$.
\end{abstract}

O dano peculiar da política, portanto, é aquele que afeta a organização dos corpos e faz da comunidade uma comunidade divida entre parcelas, e não apenas dominação de uma sobre as outras.

Esse dano cria a comunidade divida antes mesmo de qualquer regulação e compromissos entre as partes reconfiguradas. Rancière (1996, p. 51), por isso, afirma que "o dano político não se regula - por objetivação do litígio e compromisso entre as partes". Ele é o que danifica a regulação e força um novo agenciamento regulatório. Nesse sentido, a par de qualquer regulação, diálogo ou consenso de interesses, o litígio político é aquele que gera sujeitos que assumem o dano e, assim, criam e admitem um novo lugar de fala. Os sujeitos atravessados pela política são aqueles que encaram o dano e:

"[...] conferem-lhe uma figura, inventam formas e seus novos nomes e conduzem seu tratamento numa montagem específica de demonstrações: de argumentos "lógicos" que são ao mesmo tempo reagenciamentos da relação entre a palavra e sua contagem, da configuração sensível que recorta os campos e os poderes do logos e da phoné, os lugares do visível e do invisível, e articula-os na repartição das partes e das parcelas." (RANCIÈRE, 1996, p. 51-52).

Para Rancière (1996, p. 51), apenas assumindo esse dano é que os sujeitos poderão dar uma solução tratável para a relação inconciliável entre a regulação jurídica positivada e o que ele chama de dívida inexpiável, ou seja, entre a ordenação do Direito, quando instrumento da ordem policial, e a "impossibilidade" de agir fora dele. Por exemplo, apenas quando se assumiu o "dano" de um novo modo de participação da mulheres, negros, relações homoafetivas, foi que se deu um novo tratamento para a "dívida inexpiável". Em outras 
palavras, foi que se alterou o direito, para incluir como possibilidade aquilo que era juridicamente impossível ou não reconhecido a esses sujeitos.

Nesse sentido, para Rancière (1996), o dano que uma parcela causa à própria comunidade e sua divisão do sensível, ao ser e se fazer incluída, é o que faz surgir essa mesma comunidade, enquanto uma comunidade realmente partilhada por diferentes.

\section{POLÍTICA, DANO E LINGUAGEM ESTÉTICA}

\subsection{O Pressuposto do Desentendimento}

Rancière (1996) chama a atenção, no momento em que se dedica às implicações da política na dimensão linguístico-discursiva, para a necessidade de não se perder de vista a "[...] dupla especificidade do 'diálogo' político" - lógica policial e lógica de embate igualitário -, encerrando-o (diálogo) “[...] em falsas alternativas que exigem uma escolha entre as luzes da racionalidade comunicativa e as trevas da violência originária ou da diferença irredutível." (RANCIÈRE, 1996, p. 55).

Colocar essa alternativa é pressupor, para Rancière (1996), a identificação da racionalidade política com a relação de locutores que se dirigem um ao outro, para confrontar seus interesses e seus sistemas de valores e para testar sua validade. É tomar facilmente como assertiva válida que essa identificação

[...] constitua uma descrição exata das formas do logos político racional e que por isso seja deste modo que a justiça abre seu caminho nas relações sociais: pelo encontro de parceiros que, num mesmo movimento, entendem um enunciado, compreendem o ato que o fez enunciar e tomam a seu cargo a relação intersubjetiva. Assim, a pragmática da linguagem em geral (as condições necessárias para que um enunciado faça sentido e efeito para quem o emite) forneceria o telos da troca razoável e justa. (RANCIÈRE, 1996, p. 55-56).

A referida identificação pressupõe, ainda, para Rancière (1996), a antecipação de uma situação ideal ainda não dada. Em outras palavras, na lógica do discurso pragmático, o locutor se vê obrigado, para o sucesso de sua comunicação, a submetê-lo a condições de validade dependentes de intercompreensões já pressupostas - se não há condições já postas de entendimento, não há sucesso na comunicação.

Rancière (1996) desenvolve seu pensamento com o seguinte raciocínio: afirma que a expressão "Você me compreende?" quer dizer, ao menos, duas coisas diferentes: compreender um problema ou compreender uma ordem. Aqueles excluídos das condições comuns de 
comunicação, diz o autor, quase sempre estão na condição de compreender ordens, quando se trabalha com a racionalidade comunicativa pragmática. A compreensão pode revelar, assim, a aceitação/imposição de enunciados produzidos por pessoas e/ou em contextos com interesses significativamente dissidentes, por isso, potencialmente opressivos.

Chegar a essa conclusão provisória não significa, para Rancière (1996), sentenciar que existe uma lei de poder que sempre marcaria com violência a língua da comunicação e sua racionalidade argumentativa. Porém, convoca o abrir os olhos para a perspectiva de que uma situação de argumentação política deve ser sempre ciente da divisão preexistente e reproduzida entre uma língua dos problemas e uma língua das ordens.

Isso implica, em suma, sempre se voltar à necessidade de submeter os discursos às suas condições de validade, o que é obtido ao se colocar em litígio o modo como cada uma das partes participa da construção do compreender (RANCIÈRE, 1996, p. 58). É voltar-se à tensão entre a parcela dos falantes e os falantes sem-parcela.

Nesse caminho, por exemplo, a resposta à pergunta "Você me compreendeu?" deve conduzir à constituição de uma cena de palavra específica, em que se deve fazer outra relação, explicitando a posição do enunciador, antes de se pensar o enunciado propriamente dito. Desse modo, o enunciado, assim problematizado, vê-se extraído da situação de palavra em que funcionava de maneira automatizada, enquanto é colocado em outra situação na qual pode não funcionar mais da mesma forma, passando a ser objeto de exame e não de ordem. Esse movimento, ele sim, entrega o enunciado ao estatuto de uma língua efetivamente comum - a "língua comum do desentendimento" (RANCIÈRE, 1996, p. 58).

Explica-se. Esse âmbito de linguagem comum é aquele em que se compreende que o enunciado em si não é comum, porque colocado em situações de fala diferentes e que, por isso, se não contestados, reproduzem lógicas de ordem. Todavia, ao mesmo tempo, há uma dimensão linguística comum, por meio da qual é que se pode estar ciente de algo comum: a diversidade de situações das quais partem os interlocutores (RANCIÈRE, 1996, p. 58).

Pode-se dizer que, para Rancière (1996), o chegar a essa língua comum que admite a diferença das condições de fala é a querela primeira que se encontra no âmago de toda a argumentação política (na perspectiva como o autor a vê).

A tomada de consciência dessa querela se faz necessária, pois, segundo Rancière (1996), ao se enunciar uma ordem, esta, ao ser compreendida, pode significar simplesmente 
que foi uma ordem bem dada. Porém, disso se pode deduzir outra consequência, segundo o autor, totalmente desconcertante: se o inferior entendeu bem a ordem dada pelo superior, significa que participa da mesma comunidade dos seres falantes, quer dizer que é seu igual. Daí, pode-se deduzir que a desigualdade das posições sociais somente funciona em razão da própria igualdade dos seres falantes, que são capazes de enunciar e compreender as ordens de manutenção da organização estabelecida (RANCIÈRE, 1996, p. 60). Diante disso que se faz pertinente a querela da política, a qual busca desterrar as condições de fala, acusando as incoerências opressivas do entendimento consensual, a fim de dar a palavra a parcelas que antes apenas reproduziam os interesses enunciados por outros.

Segundo Rancière, deve-se afastar, nesse sentido, a ilusão copérnica de que o "[...] entendimento da linguagem não tem consequência para a definição da ordem social." (RANCIÈRE, 1996, p. 60).

Para o autor, diante disso, quem quiser continuar admitindo que há possibilidade de entendimento comum está obrigado a reconhecer que uma ordem hierárquica em relação desigual somente pode ser perpetuada porque existe a igualdade dos falantes. Em contrapartida, se quiserem defender uma linguagem comum e, ao mesmo tempo, ser contra os processos de desigualdade e exclusão, devem fazê-lo admitindo que o que há de comum é a diferença de modos de ser, logo, o que há de comum é o desentendimento (RANCIÈRE, 1996, p. 60). Ver por esse prisma é entender que há entendimento no conflito e no desentendimento; que o consenso possível é que existe desentendimento e que, assim, há um plano linguístico comum que nos permite perceber que os sujeitos não são e nunca serão totalmente iguais em seus lugares enunciativos.

O desentendimento, assim, não diz respeito apenas à palavra, mas se origina na própria situação dos que falam; diz respeito não à argumentação mais ao argumentável (RANCIÈRE, 1996, p. 13). Rancière explica que a situação de extremo de desentendimento:

“[...] é aquela em que $\mathrm{X}$ não vê o objeto comum que $\mathrm{Y}$ lhe apresenta porque não entende que os sons emitidos por Y compõe palavras e agenciamentos de palavras semelhantes aos seus. (...) As estruturas de desentendimento são aquelas em que a discussão de um argumento remete ao litígio acerca do abjeto da discussão e sobre a condição daqueles que o constituem como objeto. (1996, p. 13).

O desentendimento, em outras palavras, pode ser visto na situação em que dois interlocutores falantes conhecem o léxico um do outro, sabem que ambos se comunicam, mas o agenciamento desse logos (útil e nocivo/justo e injusto) para um é diferente do agenciamento do outro. Para um, por exemplo, a felicidade pode ter um objeto, mas, para 
outro, a da felicidade por ser bastante diferente, mesmo que utilizem a mesma língua para se expressarem.

A cena política, desse modo, na concepção de Rancière (1996), deve ser a cena de uma comunidade paradoxal que admite como comum o litígio, que é o desentendimento de pontos de partida. Não é a cena que identifica a política como a atividade de comunicação entre interlocutores participantes de objetos ou fins pertencentes a uma linguagem comum, ao modo, por exemplo, habermasiano. Nesse espaço deliberativo pode haver política, caso se perceba algum deslocamento do sensível por meio do reconhecimento da igualdade de parcelas de participar da definição do que acham justo, mas esse espaço não é a política. Ele pode ser o próprio instrumento da polícia, ao filtrar a participação apenas daqueles que reúnem condições de estarem ali, mantendo, assim, o mesmo rol de incluídos.

O que não significa, por outro lado, remeter a cena política ao fatalismo da incomunicabilidade das linguagens ou à impossibilidade de entendimento. A interlocução política, diz Rancière (1996), sempre amalgamou jogos de linguagem e regimes de palavra heterogêneos, processos a partir dos quais sempre se desenvolveram intrigas e argumentações compreensíveis.

O problema, para o autor, não está exatamente em saber se as pessoas que falam ("linguagens diferentes" ou de situações diferentes) podem chegar a se entender, mas está em saber se "são" ou "não são", se falam ou se apenas produzem ruído (RANCIÈRE, 1996, p. 61). Está em saber “[...] se a linguagem comum na qual expõem o dano é, realmente, uma linguagem comum. A querela não tem por objeto os conteúdos de linguagem mais ou menos transparentes ou opacos. Incide sobre a consideração dos seres falantes como tais." (RANCIÈRE, 1996, p. 61).

Desse modo, segundo Rancière (1996), em toda discussão social em que há efetivamente algo a ser discutido, a estrutura que está implícita é aquela em que os objetos e os sujeitos estão, eles próprios, em litígio e em teste. Antes de qualquer embate de interesses e valores, antes de qualquer submissão de pretensões de validade, há o litígio em torno do objeto do conflito, o litígio em torno da existência do próprio litígio e das partes que nele se conflitam. Nesse desvelar do litígio entre os falantes, que é o desvelar do desentendimento, está a possibilidade do deslocamento da divisão do sensível levado a cabo pelo dano da política. 


\subsection{Linguagem Estética e Dano Político}

Nesse ponto, entra a relevância do discurso estético como instrumento linguístico desarticulador das "formas intramundanas de argumentação e validação", como diz Rancière (1996, p. 66), lembrando uma distinção feita por Habermas. Este coloca em pólos opostos o que chama de "formas intramundanas de argumentação e validação" e as linguagens "poéticas" de abertura para o mundo.

Deve-se entender por estética, nas palavras do filósofo, todo o "sistema de formas 'a priori' determinando o que se dá a sentir. É um recorte dos tempos e dos espaços, do visível e do invisível, da palavra e do ruído que define ao mesmo tempo o lugar e o que está em jogo na política como forma de experiência" (RANCIÈRE, 2005, p.16). O estético, portanto, deve ser tomado aqui por aquilo que é dos sentidos [que mexe com os sentidos], da sensibilidade, daquilo que faz sentir como as coisas são e estão organizadas, não como aquilo que elas deveriam ser ou como se pensa que elas são. Nesse sentido, ao se referir a linguagens ou a discursos estéticos, está-se falando, também, de formas poéticas, metafóricas, artísticas, etc., que são formas que produzem novas experiências nos sentidos, nos modos de ver e ser.

As linguagens estéticas, para a Rancière, oferecem-se como instrumento reconfigurador da ordem discursiva na medida em que manifestam potencialidades próprias da política que é sempre, a um só tempo, “[...] argumentação e abertura para o mundo no qual a argumentação pode ser recebida e fazer efeito, argumentação sobre a própria existência desse mundo." (RANCIÈRE, 1996, p. 66). Nesse caminho, fazem surgir a questão do universal, antes de colocar as questões da universalização possível ou impossível das pretensões colocadas em discurso (RANCIÈRE, 1996, p. 66).

Para Rancière (1996), as formas de comunicação social que fazem efeito político são, ao mesmo tempo, argumentações em uma dada situação e metáforas dessa mesma situação. Atingem seu ápice nas situações em que “[...] a pressuposição do entendimento está em litígio, em que é preciso produzir ao mesmo tempo a argumentação e a cena em que ela deve ser entendida, o objeto da discussão e o mundo em que figura como objeto.” (RANCIÈRE, 1996, p. 67).

A interlocução política é, por excelência, um caso desse tipo, segundo Rancière (1996). O fazer estético, por isso, para o autor, sempre esteve no cerne do litígio que a política 
vem inscrever frente a ordem policial, porque é próprio da estética o revelar e o mexer com a ordem sensível.

Rancière (1996) aponta que a história moderna das formas políticas está ligada à separação que fez a estética aparecer como apenas discurso sobre o sensível - como um discurso autônomo do sensível separado de todo julgamento sobre seu significado social (RANCIÈRE, 1996, p. 68 ). O resultado desse processo de “autonomização" da estética, conclui Rancière,

\footnotetext{
[...] é em primeiro lugar a emancipação das normas de representação, em segundo lugar a constituição de um tipo de comunidade do sensível que funciona sob o modo da presunção, do como se que inclui aqueles que não estão incluídos, ao fazer ver um modo de existência do sensível subtraído à repartição das partes e das parcelas. (RANCIÈRE, 1996, p. 68).
}

Para o autor, todavia o contraditório é que não houve uma "estetização" da política na modernidade, porque esta tem função estética desde seu princípio - seu objeto sempre foi a problematização da posição dos corpos no mundo e o espaço público como espaço de litígio (RANCIÈRE, 1996, p. 68). O dialogismo da política carrega mais da heterologia literária do que se imagina, muito mais de seus jogos estéticos da primeira e da terceira pessoa, do que de situações supostamente ideais do diálogo entre uma primeira e uma segunda pessoa (RANCIÈRE, 1996, p. 70). Rancière, por isso, afirma que "a invenção política opera-se em atos que são ao mesmo tempo argumentativos e poéticos, golpes de força que abrem e reabrem tantas vezes quantas for necessário os mundos nos quais esses atos de comunidade são atos de comunidade" (RANCIÈRE, 1996, p. 70).

Os atos de política revelam, desse modo, potencialidades próprias das linguagens poéticas, assim como discursos poéticos se revelam instrumentos de potencialidades políticas. Como lembra Rancière (1996), fazendo remissão a Richard Rorty, esses (política e estética) são domínios que, ao colocar os próprios motivos e termos do discurso em discussão, possibilitam: novas formas de linguagem, a redescrição de experiências comuns e a invenção de novas metáforas que, mais tarde, podem ser chamadas a integrar o campo das ferramentas linguísticas comuns (RANCIÈRE, 1996, p. 70).

Remete-se à ideia da libertação da metáfora, do filósofo italiano Gianni Vattimo, que significa a emancipação da experiência em perspectiva plural. A linguagem estética é a possibilidade de dizer a experiência de cada um não com as significações da sociedade de discurso já legitimada, mas a partir da própria realidade. Na libertação da metáfora se tem, 
assim, a negação da hegemonia do discurso unívoco (VATTIMO, 2004, p. 156), que sustenta a ordem sensível.

A linguagem poética faz escancarar que somente se interpreta com a experiência de mundo própria de cada falante. Ela evidencia a limitação histórica, de um lado, e a possibilidade polissêmica, de outro, que estão presentes em toda forma de logos.

Enquanto não se fizer a libertação da metáfora do isolamento que a fez aparecer como apenas discurso sobre o sensível, separado de todo julgamento sobre seu uso, como identificou Rancière (1996), uma sociedade estará fadada à mentira dos dominadores.

Somente ao se estabelecer uma sociedade e uma casta de dominadores nasce a obrigação de se 'mentir segundo uma regra estabelecida', ou seja, de se usar, como única língua 'apropriada', as metáforas dos dominadores, fazendo com que as outras linguagens sejam degradadas a condição de puras linguagens metafóricas, ao campo poético (VATTIMO, 2004, p. 26).

A mentira dos dominadores é aquela própria da falsa questão que pode esconder a expressão "Você me compreende?", ao camuflar linguagens de compreensão e linguagens de ordem, como referiu Rancière (1996), exprimindo estritamente a ordem do sensível que organiza a sua dominação.

A abertura polissêmica da linguagem estética para modos de ser, compreender e falar o justo e o injusto, nas suas várias posições de mundo, permite ver a contingência da ordem social e, assim, a igualdade de qualquer um dos sujeitos de ser ser-falante. Aí está o móvel político. A política existe porque existe essa polissemia sentidos, essa contingência, pois,

[...] o fundamento da política, se não é natureza, não é tampouco a convenção: é ausência de fundamento, é pura contingência de toda ordem social. Há política simplesmente porque nenhuma ordem social está fundada na natureza, porque nenhuma lei divina ordena as sociedades humanas. (RANCIÈRE, 1996, p. 30).

Entretanto, não é qualquer manifestação estética que configura-se política, vez que esta é rara e manifesta-se mediante um dano na ordem policial no momento volátil que esta se encontra com o processo de verificação de igualdade dos seres falantes:

Diante desta concepção, a dedução de que qualquer reconfiguração estética significaria uma redefinição política seria equivocada. A presença do integrante estético no político não autoriza a se estabelecer uma relação biunívoca entre estes. A reorganização dos atributos perceptíveis pode, como bem atestam os impasses presentes na cena contemporânea, reforçar as referências em ação na partilha em vigor, ao invés de aí operar efetivamente uma outra figuração política, de interromper os efeitos da sua maquinaria. Isto bem compreendido evitaria outro possível equívoco, o de se considerar que a política estaria em todo lugar, ou que 'tudo é política'. Sendo associada à transformação de animais ruidosos em seres falantes - dotados de 'logos' e fala no espaço do comum - a política, insiste o filósofo, é rara. (PALLAMIN, 2010, p. 08). 
Não obstante, é preferível aceitar o inconveniente polissêmico da linguagem metafórica e, igualmente, o dano à ordem proporcionado pela política, a viver com a consciência a qual, segundo Rancière (1996), o próprio Platão teria chegado no mito do Político depois de tentar buscar modelos na era de Cronos e nos sonhos néscios dos reis pastores, a conclusão que: “Nosso mundo gira ‘em sentido contrário' e quem quiser curar a política de seus males terá apenas uma solução: a mentira que inventa uma natureza social para dar à comunidade uma arkhé [uma origem absoluta]." (RANCIÈRE, 1996, p. 31).

\subsection{O Dano Político da Linguagem Estética em Exemplos}

O efeito da expressão estética das modalidades de relações de poder tem o potencial de gerar, como se discorreu, encontros de teor político (reconfiguração do sensível), quando torna o que era banal e anônimo em objeto de arte, atribuindo-lhe visibilidade efetiva. Rancière (1996), não por coincidência, afirma que a revolução artística moderna possibilita dar tempo aos sujeitos de estarem no espaço das discussões públicas, ao propor a partilha democrática do sensível, o que pode ser creditado ao seu alto grau de abertura e subjetividade.

O dano político pode, nesse sentido, ser impulsionado por manifestações estéticas de diversos tipos, não apenas pelas manifestações de estirpe literária, mas também por meio da música, do teatro, da dança, do grafite, de performances e de outras formas de arte.

Um exemplo de ação de dano político-estético na seara jurídica pode ser tirado de uma decisão do Tribunal Federal do Trabalho Alemão que legitima uma ação coletiva dos trabalhadores na modalidade flash-mob ${ }^{3}$. A ação envolveu cerca de quarenta pessoas que foram convidadas a dançar e perturbar o ritmo de trabalho nas lojas de varejo (ou seja, não envolvia somente os trabalhadores da empresa contestada), retirando os artigos de venda do seu devido lugar, enchendo os carrinhos de compra para depois abandoná-los nas lojas, para que melhores salários fossem estabelecidos nas convenções coletivas.

A ação foi considerada legítima pelo Tribunal, pois apesar de não ser protegida pelo direito de greve, é abrangida pela liberdade de associação profissional garantida pela

\footnotetext{
${ }^{3}$ Em inglês, Flash Mob é a abreviação de "flash mobilization", que significa mobilização rápida, relâmpago. Trata-se de uma aglomeração instantânea de pessoas em um local para realizar uma ação organizada, geralmente planejada mediante redes sociais. Para efeitos de impacto, a dispersão geralmente é feita com a mesma instantaneidade.
} 
Constituição Alemã (art. $9^{\circ}$, parágrafo $3^{\circ}$ ) . Em trecho da decisão, o Tribunal ressalta que o artigo constitucional referente à liberdade de associação profissional deve ser interpretado de forma ampla para que seja capaz de comportar as novas modalidades de luta coletiva trabalhista que renovam permanentemente suas formas de manifestação:

\begin{abstract}
Posteriormente, nos cabe analisar o enquadramento de ações flash-mob organizadas por sindicatos que buscam melhores condições salariais. É uma atividade específica de coalizão do sindicato. Isto não significa que tais ações flash-mob até agora atípicas não devam ser reconhecidas por não estarem presentes na história de luta do trabalho, pois representam mais uma nova arma trabalhista. A proteção do artigo 9, parágrafo $3^{\circ}$ da Constituição abrange não somente meios de lutas históricos, vez que não se trata de uma descrição numerus clausus. Pelo contrário, é parte da liberdade de coalizão constitucional proteger novas formas de luta para ajustar suas armas às novas circunstâncias, a fim de manter uma correspondência de forças com o empregador, para alcançar acordos salariais equilibrados (TRIBUNAL FEDERAL DO TRABALHO, acórdão Az: 1 AZR 972/08, 22.06.2009, tradução nossa ${ }^{4}$ )
\end{abstract}

Observa-se neste caso a estética da dança e da perturbação foram utilizadas como forma de comunicação entre regimes separados de expressão: o Direito, a arte e a luta coletiva enquanto fatos sociais foram entrelaçados, assim como dois grupos improváveis trabalhadores-consumidores e consumidores-trabalhadores - que foram articulados como um novo sujeito não definido, reunindo o comum e o não-comum.

Outra manifestação interessante e recente que pode ser citada foi uma intervenção feita por alguns artistas e professores em um restaurante de luxo da zona sul da cidade de São Paulo chamado "Senzala". 5 A intervenção foi chamada de "Senzala nunca mais". O objetivo foi chamar a atenção para o nome do restaurante e a sua simbologia ainda nos tempos atuais, uma vez que senzala é uma expressão da Casa Grande dos tempos de escravidão oficial.

Os artistas entraram no restaurante, sentaram-se e pediram cervejas e porções. Dividiram-se em alguns grupos, espalhados por mesas diferentes no salão. Por alguns minutos, passaram desapercebidos aos olhos de quem ali estava. No entanto, eram os únicos negros no local, à exceção dos garçons e faxineiras. Em um determinado momento, três deles

\footnotetext{
4 Hiernach unterfallen streik begleitende "Flashmob-Aktionen" der Gewerkschaften, die der Verfolgung tariflicher Ziele dienen, dem Schutzbereich des Art. 9 Abs. 3 GG. Es handelt sich dabei um eine koalitionsspezifische Betätigung der Gewerkschaft. Dem steht nicht entgegen, dass derartige "FlashmobAktionen" bislang kein typisches, in der Geschichte des Arbeitskampfs schon seit längerem bekanntes und anerkanntes, sondern ein neues Arbeitskampfmittel sind. Dem Schutz des Art. 9 Abs. 3 GG unterfällt nicht nur ein historisch gewachsener, abschließender numerus clausus von Arbeitskampfmitteln. Vielmehr gehört es zur verfassungsrechtlich geschützten Freiheit der Koalitionen, ihre Kampfmittel an die sich wandelnden Umstände anzupassen, um dem Gegner gewachsen zu bleiben und ausgewogene Tarifabschlüsse zu erzielen.

5 Vide a matéria: ANJOS, Anna Beatriz. "Senzala nunca mais": intervenção artística contesta nome de restaurante em SP. Revista Forum [on-line]. Disponível em: < http://www.revistaforum.com.br/blog/2015/06/senzala-nunca-mais-intervencao-artistica-contesta-nome-derestaurante-em-sp/>. Acesso em 13 ago. 2015.
} 
saíram de cena por alguns segundos e caminharam até o banheiro. Ao retornar, usavam máscaras de ferro nos rostos e correntes nos pés. Não demorou para que chamassem a atenção. Caminhavam por entre as mesas e o barulho do metal arrastando no chão era marcante. Tentavam comer e beber o que o garçom lhes havia trazido anteriormente, mas a armadura atrelada à face não permitia. Um capataz, também personagem, acompanhava os atores com um chicote, estalando-o em suas costas a cada minuto. Ao final, gritos de "Eu tenho cabelo duro, mas não miolo mole" tomaram conta do local. As pessoas ali tiveram diferentes reações. Algumas ficaram com expressão de perplexidade, curiosas, tentando ligar os pontos para compreender. Outras riam, como se a situação fosse uma piada. O ocorrido terminou com viaturas policiais na entrada do local.

A intervenção buscou denunciar a conivência banalizada em relação ao nome do restaurante, que significou um lugar de escravidão e sofrimento, mas que foi apropriado por um estabelecimento de alto luxo, onde frequentam pessoas, na sua maioria, de classes altas da sociedade e da cor branca, com a maior normalidade. A performance fez ver o que não era visto, embora claro, acusando a utilização discursiva de um símbolo da escravidão sem qualquer questionamento e, mais do que isso, delatando como práticas como essas podem revelar a continuidade de comportamentos e linguagens de estigmatização opressiva e a falta de consideração e respeito para com uma grande parcela da sociedade brasileira. Eles não estão mais na senzala. Conforme comentou a jornalista responsável pela matéria, Anna Beatriz Anjos (2015), prestar atenção na cena era “[...] nem que por alguns segundos, correr o risco de ter empatia por aqueles corpos, imaginar-se no lugar deles e de todos os seus semelhantes." Assim, para usar as palavras de Rancière (2005, p. 17), tal ação estética consistiu em uma maneira de fazer que interveio "[...] na distribuição geral das maneiras de fazer e nas relações com maneiras de ser e formas de visibilidade" (RANCIÈRE, 2005, p. 17).

Como um último exemplo, embora se tenham muitos, pode ser lembrada a performance feita por uma modelo transexual na 19ª Parada do Orgulho LGBT (Lésbicas, Gays, Bissexuais, Travestis e Transexuais) de São Paulo, em junho deste ano de 2015, que desfilou caracterizada de Jesus Cristo crucificado. ${ }^{6}$ No alto da cruz, uma placa com os dizeres: "basta de homofobia com LGBT."

\footnotetext{
${ }^{6}$ Vide a reportagem publicada em diversos meios de comunição da mídia brasileira, por exemplo, disponível em: $<$ http://noticias.uol.com.br/cotidiano/ultimas-noticias/2015/06/08/transexual-crucificada-na-parada-gay-de-spdiz-ter-sido-ameacada-de-morte.htm.>. Acesso em 16 ago 2015.
} 
A "encenação" causou polêmica e revolta entre os religiosos e outros setores conservadores da sociedade. Sua intenção, ao utilizar esteticamente a cena de Jesus na cruz, foi acusar o comportamento histórico de preconceito, rejeição e segregação de pessoas não condizentes com o padrão da heteronormatividade. Pessoas às quais por muito tempo, e ainda hoje, foram encaradas como sem-parcelas, destituídas de reconhecimento igualitário e da tomada da palavra, seja na não liberdade de se expressarem como são, seja por não terem garantidos os mesmos direitos civis.

Em casos como os narrados, não se pode negar, a linguagem estética oferece um diferencial em potencialidade de ruptura e sensibilização, efeitos não atingidos da mesma forma pelo discurso-conceito, quando o objetivo é a desarticulação de ordens e modos de ser e fazer opressores e excludentes de parcelas.

\section{CONCLUSÃO}

Abordou-se no presente trabalho o papel da linguagem estética enquanto dimensão da política, como forma de resistência e ruptura aos discursos unívocos que mantêm a lógica policial dos parcelas sobre os não-parcelas, a partir do pensamento de Jacques Rancière.

Para Rancière (1996), a política surge quando os “clássicos” buscam pensar a parcela e o lugar de cada um na pólis, em substituição à dimensão imediata do equilíbrio de lucros e perdas ou, por exemplo, da condição de fortes e fracos (condições materiais, etc.). A política é, assim, a atividade de contagem de parcelas, anteriormente não contadas, isto é, não reconhecidas como participantes iguais da definição dos modos de ser e fazer no espaço comum. Nesse sentido, a política é o deslocamento da organização sensível e não a manutenção do estado das coisas.

Rancière propõe, por isso, nomearmos o que geralmente consideramos política conjunto de processos pelos quais se operam a agregação e o consentimento das coletividades, a organização dos poderes, a distribuição dos lugares e das funções e os sistemas de legitimação dessa distribuição - de polícia. Para política, o autor reserva uma ação antagônica: é a atividade que rompe com a configuração sensível na qual se define a parcela dos "sem parcela"; é uma série de atos que reconfiguram o espaço onde as partes, as parcelas e as ausências de parcelas se definem. 
A linguagem estética, em Rancière, revela-se como instrumento desarticulador das formas intramundanas de argumentação e validação, que são pré-ordenadas por parcelas que determinam a configuração do sensível em detrimento daqueles que não são considerados seres falantes, os "sem-parcela".

A dimensão estético-expressiva oferece possibilidades de ruptura da distribuição hierárquica de corpos e funções na ordem social, ou seja, uma reconfiguração do relacionamento entre uma parcela e uma ausência de parcela, na medida em que se expressa em crítica capaz de fazer sentir e ver a posição dos corpos na pólis e, com isso, desvelar realidades desiguais e opressivas.

Podemos exemplificar tal ruptura da ordem policial, capaz de produzir partilhas mais democráticas no âmbito jurídico, quando a performance estética é utilizada como mecanismo de ampliação de direitos e reconhecimento de parcelas da sociedade, como no caso do flashmob que foi utilizado por trabalhadores como instrumento de pressão para obter melhores salários ou no caso da denúncia de práticas discriminatórias veladas, como foi evidenciado no movimento "Senzala Nunca Mais" e na Parada do Orgulho LGBT.

Desse modo, a atividade política por meio da linguagem estética é um modo de manifestação que confronta o fluxo padrão da ordem policial que cria e mantêm subalternidades. A performance estética funciona como uma nova forma de entrelaçamento entre a ordem do logos e a divisão do sensível, apresentando-se como constituinte da configuração moderna da política.

Ressalta-se que a forma de ver estética não significa desembocar em um esfacelamento fatalista, ao apontar a heterogeneidade dos jogos de linguagem e dos pontos de partida que limitam os discursos, como se não se pudessem mais produzir pretensões narrativas (ou metanarrativas) em âmbito político; mas, ao contrário, coloca a questão de que a heterogeneidade e, assim, o desentendimento, revelados pela manifestação metafórica, ao invés de obstáculos externos, são fatores constitutivos da vida política, os quais, ao se fazer discursos, têm de ser levados em consideração. Para que, desse modo, abra-se o caminho de se assumir o dano que permite a existência de uma comunidade efetivamente divida, no sentido de ser compartilhada por diferentes. 


\section{REFERÊNCIAS BIBLIOGRÁFICAS}

ALEMANHA, TRIBUNAL FEDERAL DO TRABALHO. Acórdão Az: 1 AZR 972/08, 22 de junho 2009. Disponível em <https://openjur.de/u/171938.html>. Acesso em 13 jul. 2015.

ANJOS, Anna Beatriz. "Senzala nunca mais": intervenção artística contesta nome de restaurante em SP. Revista Forum [on-line]. Disponível em: < http://www.revistaforum.com.br/blog/2015/06/senzala-nunca-mais-intervencao-artisticacontesta-nome-de-restaurante-em-sp/> . Acesso em 13 ago. 2015.

ARISTÓTELES. Livro I - Política apud RANCIÈRE, Jacques. O desentendimento: política e filosofia. Paris: Editora 34, 1996.

GALENDE, Federico. Rancière: uma introduccion. Buenos Aires, Editorial Quadrata, 2012.

MACHADO, Frederico Viana. Subjetivação política e identidade: contribuições de Jacques Rancière para a psicologia política. Psicologia Política, vol. 13, nº 27, 2013.

PALLAMIN, Vera. Aspectos da relação entre o estético e o político em Jacques Rancière. Revista de Pesquisa em Arquitetura e Urbanismo, RISCO-USP, nº 12, 2010.

RANCIÈRE, Jacques. A partilha do sensível: estética e política. São Paulo: Editora 34, 2005.

RANCIÈRE, Jacques. O desentendimento: política e filosofia. Paris: Editora 34, 1996.

VATTIMO, Gianni. Depois da cristandade: por um cristianismo não religioso. Rio de Janeiro: Record, 2004. 